\title{
USO DESMEDIDO DE DISPOSITIVOS TECNOLÓGICOS MÓVILES EN NIÑOS, UN DAÑO
} SILENCIOSO A LARGO PLAZO

Excessive use of mobile technology devices in children, long-term silent damage

\section{Mg. Rosario Campos Soto ${ }^{1}$}

${ }^{1}$ Lic. Esp. En Pediatría, Hospital Santa María del Socorro". Ica, Perú

Editora Asociado de la Revista Científica Enfermería a la Vanguardia (REVAN). Ica, Perú.

A lo largo de la historia, la sociedad se ha desarrollado por los innumerables descubrimientos en busca de su bienestar y solucionar los problemas que se les presentaba. La historia moderna está relacionada con el avance de la ciencia, en esta etapa se ha permitido el descubrimiento científico de nuevas tecnologías que hace un siglo eran inconcebibles, pero que hoy en día pueden considerarse básicas para la mayoría de personas, ya que forman parte importante de sus vidas.

La aparición del internet, la televisión, especialmente de los dispositivos tecnológicos móviles como la Tablet y Telefonía Móvil han causado un gran impacto, pasando de ser un artículo de lujo, a convertirse en una necesidad de comunicación en la sociedad, tal es así, que hay más teléfonos móviles que número de habitantes en muchos países.

Hablar del uso de los dispositivos tecnológicos, es un tema muy amplio y de mucha responsabilidad, sin embargo, la Influencia de los aparatos móviles en la sociedad tiene ventajas y desventajas, nos permite tener acceso rápido a la información y nos facilitan los procesos de comunicación, además de ayudar a la educación y a la ecología, ejercen un gran impacto sobre el desarrollo temprano de competencias individuales y la capacidad de aprendizaje de los niños. En los últimos años las tecnologías de información y comunicación (TIC) se ha convertido, en una parte fundamental de la sociedad moderna.

El uso y mal uso de los dispositivos tecnológicos es una desventaja, y no podemos ignorar el hecho de que los niños pequeños están expuestos desmedidamente a las tecnologías móviles, en muchos domicilios, la televisión y los videojuegos son parte fundamental de la vida de los niños, situación preocupante, puesto que el contacto y acceso de las tecnologías de información y comunicación con el niño, se inicia en el hogar, y no son éstos quienes buscan estos dispositivos, sino, son los mismos padres quienes les facilitan su uso a muy corta edad, sin medir los efectos y consecuencias , creando en él, un hábito y dependencia, que con el tiempo va a traer problemas de salud, como los que ya se están reportando y advirtiendo, aumento de casos de tendinitis, problemas de conducta y lenguaje, problemas visuales a causa del uso excesivo de los videojuegos, Tablet, Smartphone, entre otros. Estudios de investigación demuestran que la exposición excesiva de los niños menores a estos dispositivos tecnológicos, es perjudicial, logra ocasionar daños psicológicos y neurológicos, puede acelerar la maduración del cerebro generando 
déficit de atención, retrasos cognitivos, problemas de aprendizaje y rendimiento escolar, aumento de la impulsividad y falta de autocontrol; así como aumentar el riesgo de conductas agresivas en personas con predisposición a estos cuadros.

Es evidente que el uso y abuso de las herramientas tecnológicas y redes sociales, trae muchas consecuencias sobre el desarrollo cognitivo, social y afectivo del niño, así como otros aspectos de su salud como el sueño, el riesgo de sobrepeso y la vida sedentaria, que podemos lamentar a futuro. Por todo esto, es necesario tomar conciencia y responsabilidad de advertir informando a la población, principalmente a los padres de familia sobre los serios riesgos y consecuencias potencialmente negativas que ocasionan los medios electrónicos en los niños y adolescentes, así mismo, preparar a los niños para una vida donde el uso de tecnologías de la comunicación sea necesario para el éxito personal y social en el futuro y prevenir, Vigilar y programar el tiempo de acceso y uso de los dispositivos móviles es de entera responsabilidad de los padres. 